\title{
Effect of Partial Replacement of Ground Granulated Blast Furnace Slag with Sugarcane Bagasse Ash as Source Material in the Production of Geopolymer Concrete
}

\author{
Parthiban KATHIRVEL *, Murali GUNASEKARAN, Sreenath SREEKUMARAN, \\ Arathi KRISHNA
}

\author{
School of Civil Engineering, SASTRA Deemed University, Thanjavur - 613401, India \\ crossref http://dx.doi.org/10.5755/j01.ms.26.4.23602
}

Received 18 June 2019; accepted 25 November 2019

\begin{abstract}
The study on the characteristics of geopolymer concrete (GPC) is of ultimate significance to instill assurance in builders and engineers. Abundant available literatures point towards the utilization of fly ash and ground granulated blast furnace slag (GGBFS) as source material in the production of GPC with little on other materials. India produces nearly 350 MMT of sugarcane for the production of sugar, which lies second only to Brazil in the annual production, the disposal of the bagasse creates an environmental issue needs to be effectively utilized. Hence, this work was intended to investigate the effect of utilizing sugarcane bagasse ash (SCBA) as a source material in the production of geopolymer mixes. The fresh (consistency, setting time, soundness and flow), hardened (density, compressive strength, expansion and $\mathrm{pH}$ ) and microstructural properties (X-ray diffraction) of the tested mixes were asessed. The results infer that $20 \%$ replacement level of GGBFS with SCBA produces superior compressive strength and all other results were within the permissible limits even at $40 \%$ replacement level.

Keywords: geopolymer concrete, alkali activated slag, sugarcane bagasse ash, microstructural behaviour, mechanical properties, alkalinity.
\end{abstract}

\section{INTRODUCTION}

Cement is the key ingredient utilized as a part of the concrete production, which has been considered as the majority of the essential substance on the planet. Concrete appears the premise of the structural business nowadays, yet it discharges $\mathrm{CO}_{2}$ at a rate of approximately 1 ton for each ton of concrete manufactured [1]. To decrease the measure of $\mathrm{CO}_{2}$ discharge from the cement business, the process of manufacturing must be enhanced to diminish its discharges of air contamination [2]. To meet the needs of sustainable development and environment preservation, new materials which are environment friendly were required to replace the conventional concrete manufactured from OPC and are termed as geopolymers. Geopolymers are a fairly innovative group of building materials that do not need C-S-H gel but make use of the polycondensation of $\mathrm{Si}$ and $\mathrm{Al}$ from source material to attain a greater strength [3]. Alkali activated binders are typically produced with an aluminosilicate precursor and an activator which is primarily consists of alkalis of $\mathrm{Na}$ or $\mathrm{K}$ and waterglass. Few investigations have inspected the impact of variables (silica fume [2], fly ash [4] and metakaolin [5]) that persuades the development of alkali activated slag (AAS) activated with common activators.

The sugar which has been extracted from sugarcane leaves behind the sugarcane bagasse which when powdered to ash termed as Sugarcane bagasse ash (SCBA), which erstwhile acknowledged as a pozzolanic material recently and to be utilized as a supplementary cementitious

\footnotetext{
* Corresponding author. Tel.: +91-4362-264101; fax: +91-4362-264120.

E-mail address: parthiban@civil.sastra.edu (P. Kathirvel)
}

material [6]. The yearly production of sugarcane globally augmented from $1910.88 \mathrm{Mt}$ in 2011 to $2013.72 \mathrm{Mt}$ in 2016. In India, the production rate increases from $342.38 \mathrm{Mt}$ in 2011 to $348.45 \mathrm{Mt}$ in 2016 as shown in Table 1 which accounts about $18 \%$ of the global sugarcane production annually second only to Brazil, which produces about $38 \%$ of the global production.

From every ton of harvested sugarcane, $104 \mathrm{~kg}$ of sugar has been produced which yields about $13 \%$ of the harvested sugarcane leaving behind $231 \mathrm{~kg}$ of bagasse ( $28 \%$ of planted sugarcane) [7, 8]. Due to its high BOD, this should not be disposed in water bodies or other sensitive ecosystems [9]. As well as, the industries are facing issues in disposing the waste from production due to its environmental issues, developing an appropriate solution to handle this waste from the sugar industry [8]. Beside these backdrop concerns, this paper deals with the utilization of incinerated SCBA as a geopolymer source material (GSM) in the production of GPC. The development in the strength and the reaction products involved in the reaction mechanism has not been addressed elsewhere, hence this work was intend to investigate the microstructural characterization of geopolymer mixes, when GGBFS has been partially substituted by SCBA. In this regard, the effect of replacing GGBFS with SCBA was investigated with the aid of physical and mechanical characteristics of the mixes and the microstructural analysis in the form of XRD analysis at various curing age.

\section{MATERIALS AND METHODS}

GGBFS of specific gravity 2.90 obtained from the local steel manufacturing plant satisfying the requirements 
of basicity coefficient, $\mathrm{CaO} / \mathrm{SiO}_{2}$ and $\mathrm{Al}_{2} \mathrm{O}_{3} / \mathrm{SiO}_{2}$ was utilized as GSM in the production of GPC.

SCBA acquired from the local Sugar Mill was whitish grey in colour with specific gravity of 2.65 was utilized as a substitution for GGBFS in the production of GPC. The chemical composition of GGBFS and SCBA were assesed using X-ray fluorescenece (XRF) study and their results are shown in Table 2. For preparing mortar specimens, sand was used with a specific gravity 2.58, fineness modulus 2.56 and water absorption of $1.37 \%$. GSMs were activated with the mixture of $99 \%$ pure $\mathrm{NaOH}$ in flakes form and $\mathrm{Na}_{2} \mathrm{SiO}_{3}$ in liquid form with $28 \% \mathrm{SiO}_{2}, 11.2 \%$ $\mathrm{Na}_{2} \mathrm{O}$ and $60.8 \% \mathrm{H}_{2} \mathrm{O}$ by mass with a modulus of silica 2.5.

Five different proportions of GGBFS replacement with SCBA were assessed in the study: $0 \%$ (control), $10 \%$, $20 \%, 30 \%$ and $40 \%$ by mass. For preparing the mixes, $\mathrm{NaOH}$ concentration was kept constant at $12 \mathrm{M}$ and ratio of $\mathrm{Na}_{2} \mathrm{SiO}_{3}: \mathrm{NaOH}$ was taken as 2.0; whereas, the sand/GSM ratio was fixed as 2.5 (the GSM being the sum of GGBFS and SCBA). The consistency and setting time of the mixes were assessed using Vicat apparatus and soundness with Le-Chateliar method. The specimens were cured under ambient temperature condition of $24 \pm 2{ }^{\circ} \mathrm{C}$ at a relative humidity of $64 \pm 3 \%$. The compressive strength of the mortar mixes was assessed after 3, 7 and 28 days of air curing on $70 \mathrm{~mm}$ cube specimens using $3000 \mathrm{kN}$ capacity compressive testing machine. The expansion of the mortar mixes were tested with a $20 \mathrm{~mm} \times 20 \mathrm{~mm} \times 100 \mathrm{~mm}$ specimens. X-ray diffraction (XRD) patterns were obtained for the paste samples after 3,7 and 28 days using Bruker, $\mathrm{D}_{8}$ Focus under an accelerating voltage of $40 \mathrm{kV}$ with an alternating current of $40 \mathrm{~mA}$ subjected to $\mathrm{CuK} \alpha$ radiation with $2 \Theta$ step size ranges from $20^{\circ}$ to $80^{\circ}$. The alkaline nature of the tested samples was measured with the help of $\mathrm{pH}$ instrument for the powdered samples diluted in distilled water for $72 \mathrm{hrs}$.

\section{RESULTS AND DISCUSSION}

\subsection{Fresh properties}

The properties of the mixes at fresh state were analyzed with the aid of consistency, setting time and soundness of the mixes and their results are detailed in
Table 3. It has been observed that the consistency of the paste increases with the increase in the replacement level of GGBFS with SCBA. For example, the paste consistency augmented from $30 \%$ for the control mix to $37 \%$ at $60 \%$ replacement level of GGBFS with SCBA. The increased consistency at higher replacement level is mainly owing to the hygroscopic temperament and higher surface area of SCBA which tends to increased water demand $[6,11]$. As the setting time is directly persuaded by the consistency of the paste, the setting time was also examined to increase with the increasing replacement level of GGBFS with SCBA. For instance, the paste setting time at room temperature has increased from $40 \mathrm{~min}$ for the control mix to 115 min, when replacing GGBFS with $40 \%$ SCBA. This is primarily owing to the moisture grasping properties of SCBA and loss of $\mathrm{C}_{3} \mathrm{~A}$ owing to the increasing hydration products results in increased duration of setting. Besides, SCBA consists of less $\mathrm{CaO}$ as GGBFS, which may as well quicken the increased setting time with the addition of SCBA. There has been a reduction in the soundness results with the increasing percentage of SCBA. For instance, it can be observed that the mixes replacing GGBFS with $40 \%$ SCBA resulted in a soundness of $1.7 \mathrm{~mm}$ comparing to $2.5 \mathrm{~mm}$ for the control mix. This is mainly due to the reduction in the amount of free $\mathrm{CaO}$ and $\mathrm{MgO}$ on inclusion of SCBA with GGBFS. Similarly, the behaviour of the concrete in the fresh condition is principally depends on the flowability of the cement paste. For which, the workability results of the mixes in the form of mortar flow for varying replacement level of GGBFS with SCBA are detailed in Table 3. It has been observed that the flow reduces with the increasing SCBA volume. For instance, the flow of the control mortar mix is $90 \mathrm{~mm}$ comparing to $71 \mathrm{~mm}$ for mixes replaced with $40 \%$ SCBA. On the whole, the size and shape of the particle as well as the filling effect plays a significant part in the workability. The resistance to flow at higher replacement level increases due to the filling capability of SCBA in the pores of GGBFS matrix resulting in increased particle contact because of the higher surface area. Also, at higher replacement level due to its porous $[5,11]$ and hydrophilic nature [12] of SCBA which attracts more water than GGBFS resulting in reduced flow at higher replacement levels.

Table 1. Production of sugarcane (in Mt) in the world and top countries [10]

\begin{tabular}{|c|c|c|c|c|c|c|c|}
\hline Year & World & Brazil & India & China & Thailand & Mexico & Pakistan \\
\hline 2011 & $\mathbf{1 9 1 0 . 8 8}$ & 734.01 & $\mathbf{3 4 2 . 3 8}$ & 115.12 & 95.95 & 49.74 & 55.31 \\
\hline 2012 & $\mathbf{1 9 6 0 . 4 8}$ & 721.08 & $\mathbf{3 6 1 . 0 4}$ & 124.04 & 98.40 & 50.95 & 58.40 \\
\hline 2013 & $\mathbf{2 0 3 1 . 7 6}$ & 768.09 & $\mathbf{3 4 1 . 2 0}$ & 128.73 & 100.10 & 61.18 & 67.46 \\
\hline 2014 & $\mathbf{2 0 1 0 . 4 0}$ & 736.11 & $\mathbf{3 5 2 . 1 4}$ & 126.15 & 103.70 & 56.67 & 62.83 \\
\hline 2015 & $\mathbf{2 0 0 4 . 5 1}$ & 750.29 & $\mathbf{3 6 2 . 3 3}$ & 117.63 & 94.14 & 55.40 & 65.48 \\
\hline 2016 & $\mathbf{2 0 1 3 . 7 2}$ & 768.68 & $\mathbf{3 4 8 . 4 5}$ & 123.06 & 87.47 & 56.45 & 65.45 \\
\hline 2017 & $\mathbf{1 9 4 6 . 3 2}$ & 758.55 & $\mathbf{3 0 6 . 0 7}$ & 104.79 & 102.95 & 56.95 & 73.40 \\
\hline
\end{tabular}

Table 2. Chemical composition of the source materials used

\begin{tabular}{|c|c|c|c|c|c|c|c|c|}
\hline Oxides & $\mathrm{CaO}$ & $\mathrm{SiO}_{2}$ & $\mathrm{Al}_{2} \mathrm{O}_{3}$ & $\mathrm{MgO}$ & $\mathrm{Fe}_{2} \mathrm{O}_{3}$ & $\mathrm{SO}_{3}$ & $\mathrm{Na}_{2} \mathrm{O}$ & $\mathrm{K}_{2} \mathrm{O}$ \\
\hline GGBFS, \% & 36.77 & 30.97 & 17.41 & 9.01 & 1.03 & 1.82 & 0.69 & 0.46 \\
\hline SCBA, $\%$ & 5.33 & 71.05 & 4.84 & 4.81 & 3.20 & 0.76 & 0.90 & 2.01 \\
\hline
\end{tabular}


Table 3. Fresh properties of the tested mixes

\begin{tabular}{|c|c|c|c|c|}
\hline Mix No. & $\begin{array}{c}\text { Consistency, } \\
\%\end{array}$ & $\begin{array}{c}\text { Setting } \\
\text { time, } \text { min }\end{array}$ & $\begin{array}{c}\text { Soundness, } \\
\mathrm{mm}\end{array}$ & $\begin{array}{c}\text { Flow, } \\
\mathrm{mm}\end{array}$ \\
\hline SCBA0 & 30 & 40 & 2.5 & 90 \\
\hline SCBA10 & 30 & 50 & 2.4 & 84 \\
\hline SCBA20 & 32 & 75 & 2.1 & 81 \\
\hline SCBA30 & 34 & 90 & 1.9 & 77 \\
\hline SCBA40 & 37 & 115 & 1.7 & 71 \\
\hline
\end{tabular}

\subsection{Density}

The flowability of the cement paste can also be influenced by the density of the cementitious material principally at reduced water-binder ratio [13]. The densities of the hardened samples were measured at the age of 3, 7 and 28 days curing and their variations in the results are shown in Fig. 1. The density was observed to increase at $20 \%$ replacement level of GGBFS with SCBA and later reduced, whereas $30 \%$ replacement level shows improved density than the control mix. The increased density of the mixes is mainly due to the lesser particle dimension and superior surface area of SCBA.

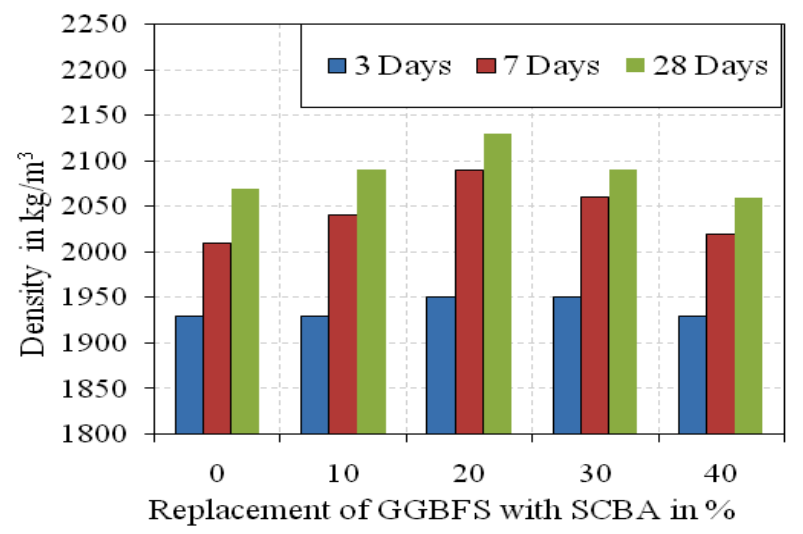

Fig. 1. Density results of the mortar mixes

It was also observed that the increased density of the mixes with the increasing curing age irrespective of the replacement level. This is primarily because of the formation of higher concentration reaction products at later ages. The behaviour is close to the cement mortar blends. The demand for water gets reduced at higher density consequently more water is discharged in the wake of packing the pores so as to cover the solid constituents resulting in lubricated cement paste [14]. In addition, large surface area of the filler material tends to increase the surface area of the solids when mixed with water resulting in higher density of the mixes $[15,16]$.

\subsection{Compressive strength}

The compressive strength results of the mortar mixes with partial inclusion of SCBA for GGBFS at the age of 3, 7 and 28 days of air curing respectively are shown in Fig. 2. The strength was estimated to enhance with the mounting age of curing and diminish with the addition of SCBA content at premature ages, whereas at higher curing age, the strength was found to enhance with the increasing SCBA content up to $10 \%$ replacement level. This is primarily as a result of the superior amount of hydration products developed at $10 \%$ SCBA volume. The development in the strength at later ages is mainly accredited to the high amount of silica, fineness and amorphous nature of SCBA [6] and its pozzolanic reactivity [17] utilized in the investigation.

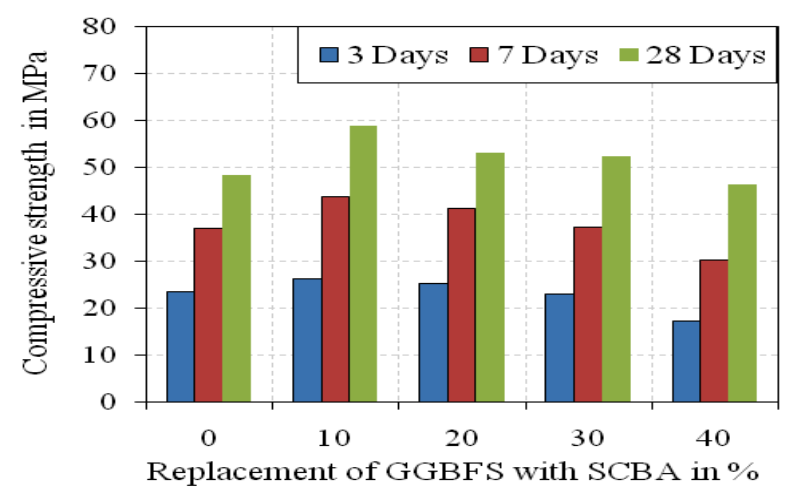

Fig. 2. Compressive strength results

The compressive strength was found to be high at $10 \%$ replacement level, whereas, $20 \%$ and $30 \%$ replacement level were comparable with the conventional mix and minor reduction after $10 \%$ replacement level may be attributed to higher water demand of the material resulting from the reduction in the flow property of the mixes [18]. The reduction may also owing to the utilization of pozzolans which leads to dilution effect.

\subsection{Expansion}

Fig. 3 demonstrates the variation in the expansion of the mixes at different curing age.

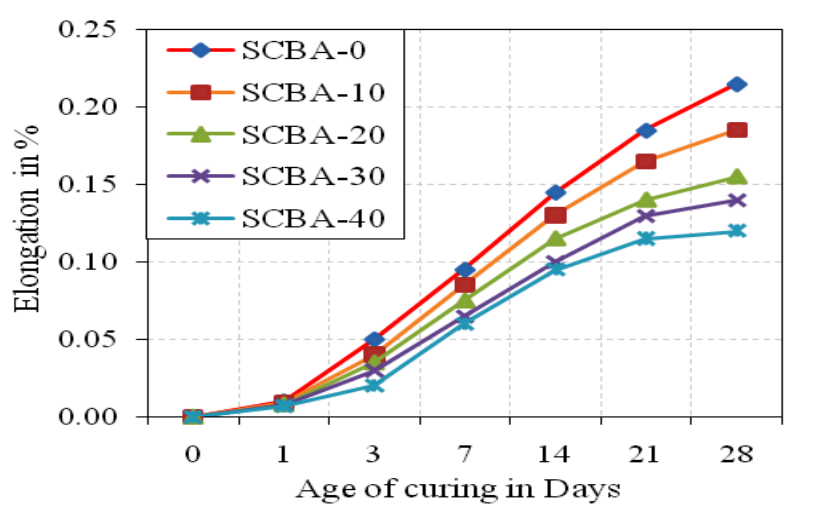

Fig. 3. Expansion results

The control specimens shows a linear increase in the expansion with the age of curing, whereas, there has been a drop in the linearity of the curves with the increasing SCBA quantity. Also, there is a reduction in the expansion results with SCBA replacement for GGBFS compared to the control specimens. For instance, there has been a reduction in the expansion of $10 \%$ and $14 \%$ for the mixes with $10 \%$ replacement at 14 and 28 days curing compared to control mixes. Similarly, $21 \%$ and $28 \%$ for $20 \%$ replacement, $31 \%$ and $35 \%$ for $30 \%$ replacement, $34 \%$ and $44 \%$ for $40 \%$ replacement was observed respectively. The reduction in the expansion with the increasing SCBA volume is principally owing to the development of the 
hydration product that controls the reaction rate by taking the alkalies due to negative charge [19]. Similar observations were made by Abbas et. al [20] when cement is partially replaced with the pozzolanic materials. The control mix showed a signs of minor surface cracks whereas the mixes with the incorporation of SCBA didn't show any signs of deterioration on the surface. This results show that the mixes with SCBA incorporation can effectively overcome the distress because of the alkali silica reaction contrast to the controlled mix without SCBA incorporation [21].

\subsection{X-ray diffraction (XRD)}

The XRD results of the samples at 3, 7 and 28 days curing for variation in the SCBA volume were studied and their results are projected in Fig. 4. The major hydration products observed in the mixes were a) Calcium Silicate Hydrate $\left(\mathrm{C}^{*}-\mathrm{Ca}_{2} \mathrm{SiO}_{4} \cdot \mathrm{H}_{2} \mathrm{O}\right) ;$ b) Calcite $\left.\left(\mathrm{C}-\mathrm{CaCO}_{3}\right) ; \mathrm{c}\right)$ Larnite $\left(\mathrm{L}-\mathrm{Ca}_{2} \mathrm{SiO}_{4}\right)$; d) Portlandite $\left(\mathrm{P}-\mathrm{Ca}(\mathrm{OH})_{2}\right)$.

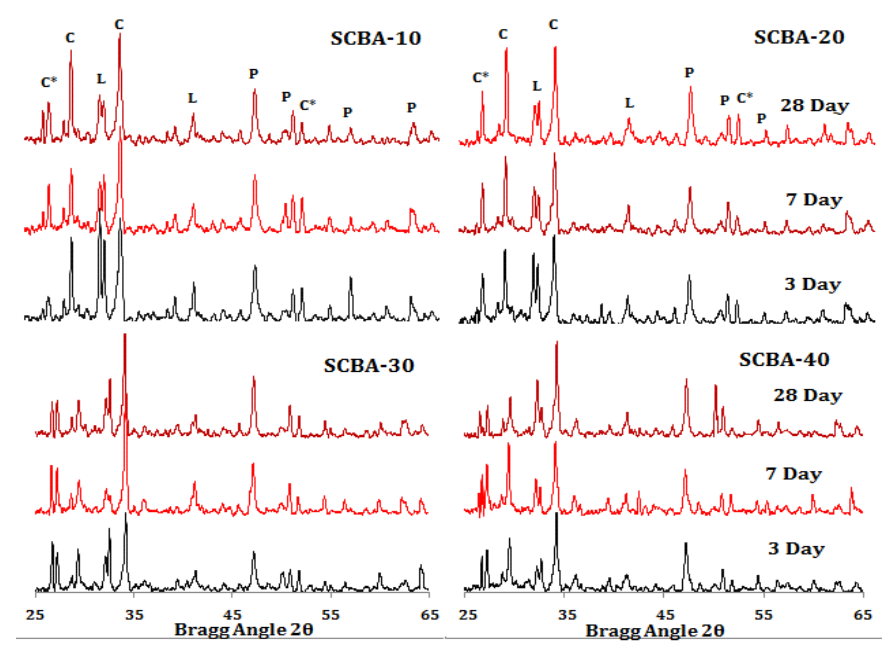

Fig. 4. XRD diffractograms for the mixes with varying replacement level

From the X-ray diffractograms, it was observed that the number and the intensity of calcium silicate hydrate and calcite increase with the increase in the quantity of SCBA as a result of the increased amount of $\mathrm{SiO}_{2}$ content in SCBA. This may lead to the increase in the compressive strength of the mixes with the increasing volume of SCBA, whereas the formation of calcite and larnite were found to be high at $10 \%$ replacement level of GGBFS with SCBA. This has led to the maximum increased compressive strength at $10 \%$ replacement level. The reduction in the strength of the mixes with the increasing level of SCBA above $10 \%$ is mainly due to the increased formation of calcite, which may leads to the formation of monocarbonates resulting in the dilution of the other hydrates by increasing the porosity of the hydrated pastes. Even with the increase in the SCBA volume, there was only a marginal reduction in the compressive strength values, which may attributed to the filler effect of Calcite at higher replacement level [22]. But, the increase in the intensity of calcite may leads to the reduction in the $\mathrm{pH}$ value resulting in the formation of carbonation. Whereas, the $\mathrm{pH}$ was maintained due to the comparable formation of Portlandite with the increasing SCBA volume and becomes more crystalline with the increase in the time of hydration which has led to the marginal increase in the $\mathrm{pH}$ value.

\section{6. pH measurement}

Fig. 5 shows the variation in the $\mathrm{pH}$ value of the mixes at 28 days of curing for different replacement level of GGBFS with SCBA. It has been observed that the $\mathrm{pH}$ values were found to be in the range of 12.38 to 12.88 and found to increase marginally with the increase in the SCBA quantity because of the reduced formation of calcite at higher replacement level which may tend to increase the $\mathrm{pH}$ value. In addition to this, due to the increased formation of Portlandite [23] may tend to increase the $\mathrm{pH}$ value. Even with no such appreciable variation, the $\mathrm{pH}$ values of the mixes were found to be within the acceptable limit which may not induce corrosion to initiate with the increasing SCBA content which enables the formation of passive layer on the top of steel bars [24] thereby reducing the effect of corrosion.

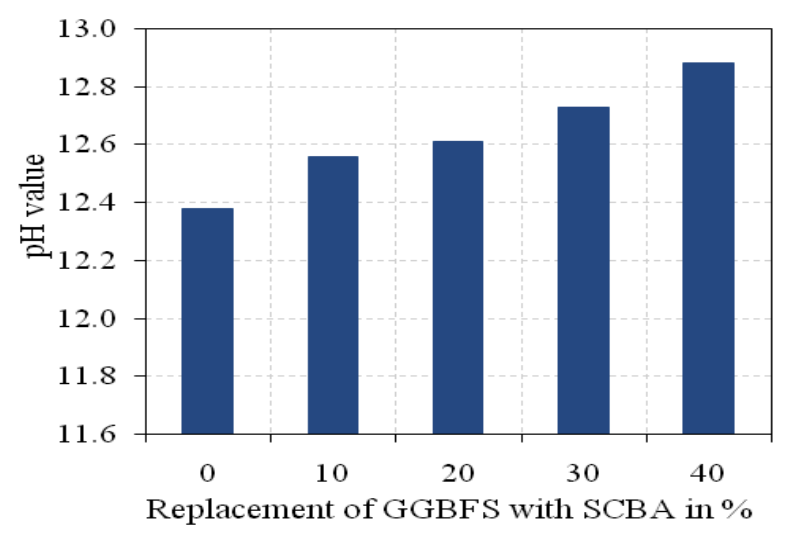

Fig. 5. $\mathrm{pH}$ measurement of the tested mixes

\section{CONCLUSIONS}

Based on the investigation carried out for replacing the GGBFS with SCBA in the production of geopolymer mortar at the rate of $0,10,20,30$ and $40 \%$ for varying age of curing, the subsequent conclusions can be made:

1. The water requirement for consistency of the control mix increases with the increase in the SCBA content which leads to the increased setting time at higher replacement level.

2. Reduction in the rate of expansion of the mortar bars was examined when GGBFS is replaced with SCBA. A distress in the alkali silica reaction was controlled at higher replacement levels.

3. The compressive strength was found to increase up to $22 \%$ compared to the control mix at $10 \%$ replacement; still up to $20 \%$ replacement gives higher compressive strength than control mix.

4. The $\mathrm{pH}$ value was found to increase with the increase in the SCBA volume due to the increased amount of Portlandite. The results were found to be within the permissible limit.

5. For up to $40 \%$ replacing GGBFS by SCBA in the production of geopolymer mixes shows advantageous results and can produce an environmentally effective cementitious mixes. 
The work can further be extended to evaluate the application of SCBA in geopolymer concrete strength and durability properties.

\section{Acknowledgments}

The authors acknowledge Aringnar Anna Sugar Mill, Thanjavur, India for supplying Sugarcane bagasse ash for this investigation. The authors also acknowledge the Management of SASTRA Deemed University, Thanjavur, India for providing the facilities to carry out the work and the encouragement in completing this work.

\section{REFERENCES}

1. Sata, V., Sathonsaowaphak, A., Chindaprasirt, $\mathbf{P}$. Resistance of Lignite Bottom Ash Geopolymer Mortar to Sulfate and Sulfuric Acid Attack Cement \& Concrete Composites 34 (5) 2012: pp. 700-708.

https://doi.org/10.1016/j.cemconcomp.2012.01.010

2. Akkarapongtrakul, A., Julphunthong, P., Nochaiya, T. Setting Time and Microstructure of Portland CementBottom As-Sugarcane Bagasse Ash Pastes Monatshefte fuer Chemie 148 (7) 2017: pp. 1355-1362. https://doi.org/10.1007/s00706-017-1953-5

3. Okoye, F.N., Durgaprasad, J., Singh, N.B. Effect of Silica Fume on the Mechanical Properties of Fly Ash BasedGeopolymer Concrete Ceramics International 42 2016: pp. $1-7$.

https://doi.org/10.1016/j.ceramint.2015.10.084

4. Kathirvel, P., Kaliyaperumal, S.R.M. Probabilistic Modeling of Geopolymer Concrete Using Response Surface Methodology Computers \& Concrete 19 (6) 2017: pp. $737-744$.

https://doi.org/10.12989/cac.2017.19.6.737

5. Chusilp, N., Jaturapitakkul, C., Kiattikomol, K. Effects of LOI of Ground Bagasse Ash on the Compressive Strength and Sulfate Resistance of Mortars Construction \& Building Materials 23 (12) 2009: pp. 3523-3531. https://doi.org/10.1016/j.conbuildmat.2009.06.046

6. Ganesan, K., Rajagopal, K., Thangavel, K. Evaluation of Bagasse Ash As Supplementary Cementitious Material Cement \& Concrete Composites 29 (6) 2007: pp. $515-524$. https://doi.org/10.1016/j.cemconcomp.2007.03.001

7. Almazan, O., Gonzalez, L., Galvez, L. The Sugar Cane, Its Byproducts and Coproducts Proceedings of AMAS. Food and Agricultural Research Council 1998: pp. 13-25.

8. George, P.A.O., Eras, J.J.C., Gutierrez, A.S., Hens, L., Vandecasteele, C. Residue From Sugarcane Juice Filtration (Filter Cake): Energy Use at the Sugar Factory Waste Biomass Valorization 1 (4) 2010: pp. 407-413. https://doi.org/10.1007/s12649-010-9046-2

9. Delgado, A.V., Casanova, C.A. Sugar Processing and ByProducts of the Sugar Industry In: FAO Agricultural Services Bulletin 144 2001: pp. 95-112.

10. Food and Agriculture Organization of the United Nations, (2012). Food and Agricultural Commodities Production (10.01.19). http://www.fao.org/faostat/en/\#data/QC.

11. Bahurudeen, A., Santhanam, M. Influence of Different Processing Methods on the Pozzolanic Performance of Sugarcane Bagasse Ash Cement \& Concrete Composites 56 2015: pp. $32-45$.

https://doi.org/10.1016/j.cemconcomp.2014.11.002
12. Ali, K., Amin, N.U., Shah, M.T. Physicochemical Study of Bagasse Ash From the Sugar Industries of NWFP, Pakistan and Its Recycling in Cement Manufacturing Journal of Chemical Society of Pakistan 31 (3) 2009: pp. 375-378.

13. Nanthagopalan, P., Haist, M., Santhanam, M., Mller, H. Investigation on the Influence of Granular Packing on the Flow Properties of Cementitious Suspensions Cement \& Concrete Composites 30 (9) 2008: pp. 763-768. https://doi.org/10.1016/j.cemconcomp.2008.06.005

14. Kwan, A.K.H., Chen, J.J. Adding Fly Ash Microsphere to Improve Packing Density, Flowability and Strength of Cement Paste Powder Technology 234 2013: pp. 19-25. https://doi.org/10.1016/j.powtec.2012.09.016

15. Nochaiya, T., Wongkeo, W., Chaipanich, A. Utilization of Fly Ash With Silica Fume and Properties of Portland Cement-Fly Ash-Silica Fume Concrete Fuel 89 (3) 2010: pp. $768-774$. https://doi.org/10.1016/j.fuel.2009.10.003

16. Wong, H.H.C., Kwan, A.K.H. Rheology of Cement Paste: Role of Excess Water to Solid Surface Area Ratio Journal of Materials in Civil Engineering $20(2)$ 2008: pp. $189-197$. https://doi.org/10.1061/(ASCE)0899-1561(2008)20:2(189)

17. Muangtong, P., Sujjavanich, S., Boonsalee, S., Poomiapiradee, S., Chaysuwan, D. Effects of Fine Bagasse Ash on the Workability and Compressive Strength of Mortars Chiang Mai Journal of Science 40 (1) 2013: pp. 126-134.

18. Ozen, S., Goncuoglu, M.C., Liguori, B., de Gennaro, B., Cappelletti, P., Gatta, G.D., Iucolano, F., Collela, C. A Comprehensive Evaluation of Sedimentary Zeolites From Turkey As Pozzolanic Addition of Cement- and Lime-Based Binders Construction \& Building Materials 105 2016: pp. $46-61$. https://doi.org/10.1016/j.conbuildmat.2015.12.055

19. Monteiro, P.J.M., Wang, K., Sposito, G., Santos, M.C.D., de Andrade, W.P. Influence of Mineral Admixtures on the Alkali-Aggregate Reaction Cement \& Concrete Research 7 (12) 1997: pp. 1899-1909. https://doi.org/10.1016/S0008-8846(97)00206-8

20. Abbas, S., Kazmi, S.M.S., Munir, M.J. Potential of Rice Husk Ash for Mitigating the Alkali-Silica Reaction in Mortar Bars Incorporating Reactive Aggregates Construction \& Building Materials 132 2017: pp. 61-70. https://doi.org/10.1016/j.conbuildmat.2016.11.126

21. Kazmi, S.M.S., Munir, M.J., Patnaikuni, I., Wu, Y.F. Pozzolanic Reaction of Sugarcane Bagasse Ash and Its Role in Controlling Alkali Silica Reaction Construction \& Building Materials 148 2017: pp. 231-240. https://doi.org/10.1016/j.conbuildmat.2017.05.025

22. Wang, D., Shi, C., Farzadnia, N., Shi, Z., Jia, H., Ou, Z. A Review on Use of Limestone Powder in Cement-Based Materials: Mechanism, Hydration and Microstructures Construction \& Building Materials 181 2018: pp. 659-672. https://doi.org/10.1016/j.conbuildmat.2018.06.075

23. Wang, K., Nelsen, D.E., Nixon, W.A. Damaging Effects of Deicing Chemicals on Concrete Materials Cement \& Concrete Composites 28 (2) 2006: pp. 173-188. https://doi.org/10.1016/j.cemconcomp.2005.07.006

24. Bohni, H. Corrosion in Reinforced Concrete Structures, CRC Press, Boca Raton, Boston New York Washington, DC, 2005. 